\title{
OBITUARI
}

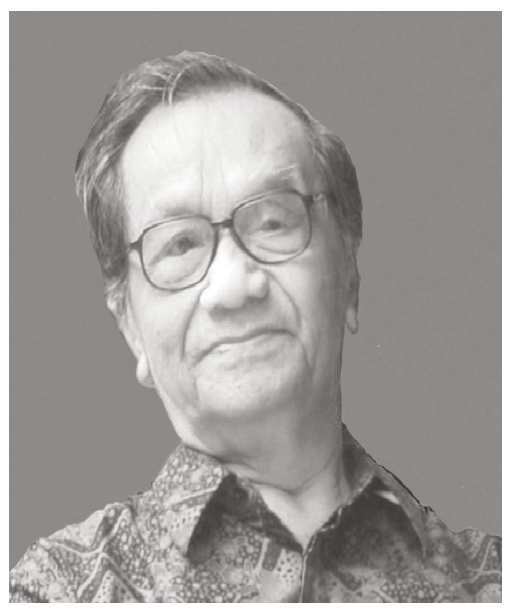

\section{Prof. (Emer.) Dr. Ir. Haryono Semangun 1930-2016}

\author{
Christanti Sumardiyono \\ Departemen Hama dan Penyakit Tumbuhan \\ Fakultas Pertanian, Universitas Gadjah Mada \\ Jln. Flora 1, Bulaksumur, Sleman, Yogyakarta 55281
}

Mendiang Prof. Haryono Semangun dilahirkan di Desa Tingkir, Salatiga pada hari Jumat Kliwon, 15 Agustus 1930 dari pasangan Samuel Semangun dan Linie Mutiari. Prof. Haryono menikah dengan ibu Sri Rejeki pada 4 Juni 1953, dan dikaruniai 5 anak yaitu Heru Purnomo, Irawati Ardani, Wisnu Sadono, Widiananto Santoso, dan Sri Tisnowati, serta $10 \mathrm{cucu}$. Beliau wafat pada Kamis, 26 Mei 2016 di Rumah Sakit Sarjito, Yogyakarta.

Beliau memulai pendidikan di Sekolah Rakyat (Volkschool) pada tahun 1935 di Popongan, Karanganyar, Surakarta hingga kelas lima, meskipun kemudian tetap mendapatkan ijazah. Kemudian, beliau melanjutkan ke Sekolah Angka Loro (Vervolgschool) di kota yang sama. Pada tahun 1941 beliau masuk sekolah Mardi Oetomo School di Karanganyar, sampai pertengahan tahun 1941 dan dilanjutkan di Christelijke Schkelschool, Klaten. Kedatangan balatentara Jepang menyebabkan sekolah-sekolah ditutup. Pada tahun 1942 beliau masuk Sekolah Rakyat (Kukumin Gakkoo), Sanggrahan, namun harus masuk ke kelas lima lagi. Tahun 1943 beliau ikut ujian masuk kelas enam di Sekolah Rakyat Prambanan. Agar dapat melanjutkan pelajaran di sekolah menengah, para murid harus menempuh ujian di Yogyakarta. Akhirnya, beliau diterima di Sekolah Menengah Pertama Negeri I, Yogyakarta pada tahun 1944. Pada waktu kelas dua SMP, beliau turut berperang pada Pertempuran Kotabaru. Dan pada saat Proklamasi Kemerdekaan Republik Indonesia dikumandangkan, beliau adalah salah satu murid di SMP Negeri I kelas dua C dan berusia 15 tahun. Pada tahun 1946 beliau mengikuti ujian SMP hingga lulus, dan dapat diterima di Sekolah Menengah Atas Bagian B, Kotabaru, Yogyakarta (sekarang bernama SMA 3 Padmanaba). Beliau hanya bersekolah di SMA Padmanaba selama dua bulan. Saat kelas dua, beliau pindah ke SMA Peralihan Solo (selama enam bulan), lalu pindah lagi ke SMA Bopkri 3 (selama sembilan bulan) dan lulus dengan nilai sangat baik pada bulan Mei 1950.

Beliau masuk Fakultas Pertanian UGM pada tahun 1950 [pada saat itu bernama Fakultit Pertanian Universitit Gadjah Mada (UNGM)], dan lulus tingkat Sarjana Muda pada tahun 1955, dan disusul lulus dari Fakultas Pertanian UGM pada tahun 1956. Beliau bekerja sebagai Pembantu Ilmiah (Wetenschapplijk Medewerker) di Sekolah Tinggi Pertanian (Landbouwhogenschool), Wageningen, Netherland dari tahun 1965-1967. Beliau lulus dari Program Doktor di Fakultas Pertanian UGM pada tahun 1968 dengan predikat Cumlaude. Beliau adalah Doktor Pertama di Bidang Pertanian lulusan UGM, dengan judul disertasi "Penelitian tentang penyakit bulai 
(Sclerospora maydis) pada jagung, khususnya mengenai cara bertahannya cendawan". Beliau diangkat sebagai Guru Besar di bidang Ilmu Penyakit Tumbuhan pada tahun 1971 dengan pidato pengukuhan berjudul: "Fitopatologi Tropika, satu aspek fitopatologi yang memerlukan perhatian khusus" pada tanggal 19 November 1971.

Di bidang manajemen, Beliau kemudian mengikuti kursus bidang manajemen universitas di University of Wisconsin, Madison, USA pada tahun 1971, selain kursus pendek dalam bidang manajemen dan life skill dalam kurun waktu 1980-1987.

Beliau berjasa besar di bidang organisasi profesi karena memprakarsai berdirinya Perhimpunan Fitopatologi Indonesia (PFI) pada tahun 1970, dan sekaligus menjadi ketua yang pertama (1970-1972). Pada saat pendirian PFI, Prof. Mien A. Rifai pernah menyampaikan bahwa Prof. Haryono adalah sosok di balik kejayaan organisasi profesi ini. Keberanian beliau menyelenggarakan Kongres PFI II pada bulan September 1972 di Yogyakarta yang sekaligus digabungkan dengan penyelenggaraan South East Asia Regional Symposium on Plant Diseases in the Tropics yang berskala internasional memicu organisasi profesi ilmiah Indonesia yang lain untuk berupaya melebarkan kiprahnya pada skala global. Oleh karena itu, maka PFI menjadikan beliau sebagai salah seorang anggota kehormatan, penghargaan tertinggi yang bisa diberikan oleh organisasi profesi ilmiah ini. Hingga kini, Perhimpunan Fitopatologi Indonesia (PFI) selalu melaksanakan kongres dan seminar ilmiah secara teratur setiap dua tahun sekali, dan beliau tidak pernah absen untuk menghadiri perhelatan ini sejak tahun 1970 hingga tahun 2011 di Universitas Sebelas Maret, Surakarta. Beliau batal hadir pada Kongres Seminar PFI XXII di Padang, Sumatera Barat pada tahun 2013 karena sakit.

Organisasi profesi lain yang beliau bidani kelahirannya, dan menjadi Ketua Tingkat Nasional adalah Asosiasi Teh Indonesia (ATI) di Bandung pada tahun 1975, dan Weed Science Society of Indonesia (WSSI) - sekarang bernama Himpunan Ilmu Gulma Indonesia (HIGI) — pada tahun 1974.

Dalam bidang ilmiah, khususnya Ilmu Penyakit Tumbuhan, jasa beliau sangat besar. Sumbangan terbesar beliau bagi Ilmu Penyakit Tumbuhan (Fitopatologi) adalah lima buku yang beliau tulis, yaitu: Pengantar Ilmu Penyakit Tumbuhan, PenyakitPenyakit Tanaman Pangan, Penyakit-Penyakit Tanaman Hortikultura, Penyakit-Penyakit Tanaman Perkebunan, dan Host Index of Plant Diseases in Indonesia yang semuanya diterbitkan oleh Percetakan Universitas Gadjah Mada (Gadjah Mada University
Press). Buku-buku tersebut dicetak ulang beberapa kali, dan hingga saat ini masih menjadi acuan penting di bidang Ilmu Penyakit Tumbuhan. Oleh karena itu, Prof. Haryono Semangun pernah mendapat penghargaan sebagai Penulis Buku Tebal Terlaris yang diterbitkan Gadjah Mada University Press pada 30 Juni 2005. Beliau mengatakan bahwa bukubuku tersebut adalah persembahan atau donasi beliau untuk ilmu pengetahuan dan masyarakat. Di samping itu, beliau menulis banyak artikel ilmiah di banyak pertemuan ilmiah dan berbagai jurnal ilmiah sebanyak lebih dari 96 judul publikasi. Publikasi-publikasi tersebut menggambarkan luasnya pengetahuan Prof. Haryono Semangun dan bidang ilmu yang dipelajari. Meski demikian, beliau selalu konsisten dengan bidang ilmu utamanya yaitu Ilmu Penyakit Tumbuhan (Fitopatologi). Tulisan-tulisan beliau dimulai dari Ilmu Penyakit Tumbuhan yang masih sangat sederhana sampai dengan Ilmu Penyakit Tumbuhan yang berbau molekuler, antara lain Boom and Burst Cycle - Interaksi Tumbuhan dan Mikroorganisme (Refleksi 60 tahun Sesudah Publikasi Spiral Lengkap) yang ditulis tahun 2010 dan dimuat dalam Majalah Bios 4 (1): 12-14.

Prof. Haryono Semangun selalu memperhatikan keberadaan jurnal ilmiah. Beliau menginginkan agar ilmu yang telah dipelajari, terutama berdasarkan hasil penelitian, dapat dibagikan kepada orang lain melalui publikasi jurnal ilmiah. Hal ini tampak dalam kiprah beliau dengan turut mendirikan dan mengelola beberapa jurnal ilmiah yaitu Ilmu Pertanian (Agriculture Science) Fakultas Pertanian UGM (1970); Warta BPTK, Balai Penelitian Teh dan Kina, Gambung, Bandung (1974); Jurnal Ilmiah Internasional Review of Tropical Plant Pathology, Today and Tomorrow's Publisher, New Delhi, India (1984); Jurnal Perlindungan Tanaman Indonesia (JPTI), Jurusan Hama dan Penyakit Tumbuhan, Fakultas Pertanian UGM, Yogyakarta (1987); Jurnal Fitopatologi Indonesia, Yogyakarta (1990); dan Jurnal Ilmiah Organisme, Fakultas Biologi, Universitas Kristen Satya Wacana (2004).

Sumbangsih Prof. Haryono di bidang pendidikan dan penelitian terlihat dengan kiprah beliau dalam pembukaan/pengembangan unit pendidikan dan penelitian, di antaranya Fakultas Ilmu Hayat/ Biologi Universitas Kristen Satya Wacana (UKSW). Salatiga (1962); Fakultas Ilmu Pasti dan Ilmu Alam (FIPIA), UKSW, Salatiga (1962); Fakultas Pertanian UKSW, Salatiga (1967); Balai Penelitian Teh dan Kina (BPTK), Gambung Bandung dengan cabangnya di Simalungun, Pematang Siantar — sekarang menjadi Pusat Penelitian Teh dan Kina (PPTK), Gambung(1973); Lembaga Pendidikan Perkebunan Cabang 
Medan (LPP), yang berkembang menjadi Politeknik Perkebunan di Yogyakarta dan Medan (1984); dan Sekolah Tinggi Ilmu Ekonomi (STIE) Wira Wacana, Waingapu, NTB (1997).

Ilmu manajemen yang telah beliau pelajari ternyata berguna ketika memperoleh amanah berbagai jabatan struktural, antara lain sebagai Pejabat Dekan dan Dekan Fakultas Pertanian UGM (1967-1973) dan Direktur Utama PT Pagilaran (milik Fakultas Pertanian UGM) di Kabupaten Batang pada masa yang sama; anggota Inter-Asian Corn and Sorghum Program, Rockefeller Foundation (1969-1973); Direktur Balai Penelitian Teh dan Kina, Gambung, Bandung (1973-1982); Direktur Lembaga Pendidikan Perkebunan (LPP), Yogyakarta dan Medan (19821987); anggota Dewan Pengawas (Komisaris) Bank Bumi Daya, Jakarta (1970-1980); anggota Dewan Pengawas (Komisaris) PT/PN Perkebunan XIX di Klaten sebagai penghasil tembakau cerutu (19821988); anggota Dewan Komisaris PT Perkebunan VI, Medan, komoditas kelapa sawit, kakao, dan karet (1984-1987); anggota Dewan Komisaris PT Madubaru/PG-PS Madukismo, Yogyakarta, komoditas gula dan alkohol/spiritus (1988-1998); dan anggota Dewan Komisaris PT Pagilaran Batang, komoditas teh dan kakao milik Fakultas Pertanian UGM.

Sebagai seorang pendidik dan dosen Fakultas Pertanian UGM, sejak awal beliau mengampu mata kuliah Ilmu Penyakit Tumbuhan, Penyakit-Penyakit Tanaman Perkebunan, dan Metode Ilmiah di Program Sarjana, serta Ilmu Penyakit Tumbuhan Lanjut, Fitopatologi Tropika, dan Filsafat Ilmu di Program Pasca Sarjana (S2 dan S3). Beliau sangat berdisiplin dalam mengajar. Misalnya, ketika beliau menjabat sebagai Direktur Balai Penelitian Teh dan Kina, Gambung, Bandung, mahasiswa tingkat doktoral Fitopatologi Fakultas Pertanian UGM mendapat kuliah sekaligus akomodasi untuk mengikuti kuliah dan bimbingan penelitian untuk skripsi di kediaman beliau di Jalan Cihampelas, Bandung dan Balai Penelitian Teh dan Kina, Gambung. Prinsip beliau, mahasiswa tidak boleh terhambat kuliahnya. Selama berkarier sebagai dosen di Fakultas Pertanian Universitas Gadjah Mada, beliau telah membimbing dan meluluskan 18 doktor.

Dedikasi Prof. Haryono yang luar biasa kemudian diganjar dengan berbagai penghargaan, yaitu Satya Lancana Karya Satya Klas I SK no.
032/TK/1980; Veteran Pejuang Kemerdekaan RI, 1981 NPV 11.002.109. dengan Skep no. 1218/x/1981, 30 Oktober 1981; Penghargaan Kesetiaan (UGM), no. UGM/57/KP/05/16, 1984; Penghargaan Kesetiaan Mengabdi 25 tahun. UGM No. 5/1983, 19 Desember 1984; Satya Lancana Karya Satya 30 tahun. SK Presiden RI No. 006/TK/2000, 28 Februari 2000; Penulis Buku Tebal Terlaris yang diterbitkan Gadjah Mada University Press, Yogyakarta, 30 Juni 2005; Anugerah Sewaka Winayaroha, Penghargaan Pengabdian Pendidikan Tinggi, Departemen Pendidikan Nasional, No. 54a/DIKTI/Kep/2006, 10 Oktober 2006.

Semasa hidupnya, mendiang Prof. Haryono telah melaksanakan Tridharma Perguruan Tinggi secara lengkap. Ilmu yang ditimba dari berbagai sumber di dalam maupun luar negeri telah beliau sumbangkan melalui berbagai pertemuan ilmiah di dalam dan luar negeri serta publikasi pada berbagai jurnal ilmiah. Negara-negara yang pernah beliau kunjungi di Asia adalah Malaysia, Thailand, Filipina, Taiwan, India, Sri Lanka, Jepang, dan Papua Nugini; Australia; Amerika adalah Amerika Serikat, Kuba, Meksiko, Brasilia; Afrika: Mesir, Kenya, Rwanda dan Zaire; Eropa: Belanda, Belgia, Perancis, Inggris, Jerman Barat, Jerman Timur, Swiss, Cekoslowakia, dan Italia.

Prof. Haryono Semangun adalah sosok ilmuwan yang rendah hati, dan selalu menganggap pendapat orang lain penting untuk didengar. Beliau dikenal sebagai seorang yang sangat kebapakan dan tidak pernah marah, namun selalu konsisten dan tegas dalam mempertahankan kebenaran.

Selamat Jalan Prof. Haryono, menuju keabadian.

\section{Bahan bacaan:}

1. Haryono Semangun: Inspirator dan Motivator. Buku Kenangan Dasa Windu Prof. Dr. Ir. Haryono Semangun 15 Agustus 1930-15 Agustus 2010. Penyunting: Christanti Sumardiyono, Budi Rahardjo, Ferry F. Karwur, Martanto Martosupono, dan Widiastuti.

2. Liputan Khusus: Wawancara singkat dengan Prof. Mien A. Rifai - Haryono Semangun dan Fitopatologi Indonesia. Dalam: Haryono Semangun Penganggu Penyakit Tanaman. Bios 4(2): 25-26.

3. Liputan Khusus: Suroto - Prof. Haryono Tidak Pernah Marah. Bios 4(2): 29. 